\title{
Morphometric Study of Proximal end of Femur of Nepalese People
}

\section{Rajeev Mukhia ${ }^{1}$, Phanindra Prasad Poudel ${ }^{1}$, Chacchu Bhattarai ${ }^{1}$, Sidharth Timsina ${ }^{2}$}

${ }^{1}$ Assistant Professor, Department of Anatomy, Manipal College of Medical Sciences, Pokhara, Nepal.

${ }^{2}$ Assistant Professor, Department of Forensic Medicine, Manipal College of Medical Sciences. Pokhara, Nepal.

Received: November 20, 2018

Accepted: December 30, 2018

Published: Jan 30, 2019

Cite this paper:

Mukhia R, Poudel P P. Morphometric Study of Proximal end of Femur of Nepalese People. Nepal Journal of Medical Sciences 2019;4(1):9-14.

\section{ABSTRACT}

Introduction: The femur is the largest and strongest bone of the body that forms the skeleton of the thigh. The morphometry of proximal end of femur are variable between different individuals with different Nationality. The aims and objective of the study is to find out the morphometric measurements- Femur Length, Femur head diameter, Femur neck shaft angle, and Femur neck length, breadth and thickness.

Methods: A total of 75 femurs of both sex were collected from the Department of Anatomy, MCOMS, Pokhara. The parameters on proximal femur were measured manually with the help of measuring scale, thread, protector and vernier calliper. The collected data were analyzed with Microsoft Excel 2007 software and represented graphically.

Results: In the present study, the average femoral length for entire femur was $42 \pm 2.81 \mathrm{~cm}$, femoral head diameter was $13.05 \pm 0.9 \mathrm{~cm}$, femoral neck length was $4.12 \pm 0.32 \mathrm{~cm}$, femoral neck breadth was $2.94 \pm 0.30 \mathrm{~cm}$, and femoral neck thickness was $2.36 \pm 0.42 \mathrm{~cm}$. The femur neck shaft angle of left femur was significantly higher than that of right femur (P-value 0.03$)$. There was no difference between other dimensions of proximal end of right and left femur.

Conclusion: The results of the present study show that the dimensions of proximal femur in Nepalese Population are different as compared to other countries population. The knowledge of different dimensions of proximal femur will be important in anthropological and medicolegal practice for sex determination and as well as to radiologists and orthopaedic surgeons for diagnosis and planning of treatment.

Key words: femur; femur head; morphometry; neck shaft angle

Correspondence: Dr. Rajeev Mukhia, Ph.D,

Department of Anatomy, Manipal College of

Medical Sciences, Pokhara, Nepal.

Email: rajeev510@yahoo.com 


\section{INTRODUCTION}

The femur is the longest, strongest and heaviest bone of human body.[1] It has upper and lower ends, and an intervening shaft. The upper end consists of head, neck, greater and lesser trocanters.[2] The upper part of the femur articulates with the acetabulum of the hip bone to form ball and socket variety of synovial hip joint.[3]

The femoral neck is approximately five $\mathrm{cm}$ long. It connects the femoral head to the shaft at an average angle of $127^{\circ}$.[4] The femur neck shaft angle is widest at birth and diminishes gradually until the age of 10 years.[5] This angle varies between individuals and between populations.[6] The morphometry of proximal femur is an important parameter in the design and preparation of implant for total hip replacement.[7]

The morphometry of proximal femur is variable between different individuals with different nationality. Therefore, this study aims to study the morphometry of proximal end of femur of Nepalese subjects and compare with other studies.

\section{METHODS}

The cross sectional, descriptive, observational study was carried out on 75 dry adult femurs of both extremities ( 35 were of right side and 40 were of left side), in the Department of Anatomy, Manipal College of Medical Sciences, Pokhara, from September 2018 to December 2018. After ethical review and permission from the concerned authorities, the normal femurs were collected from the Osteology laboratory of Anatomy. The femurs were retrieved from cadavers of Nepalese origin aged between 30 to 60 years with irrespective of sex. Femur with any fracture or pathological abnormalities like tumours, deformities, fractures, and trauma were excluded from the study.

The side determination was done for the entire femur and following parameters were measured in the study:

1. Femur length (FL): the distance between the highest point of femur head to the lowest point of the medial condyle [Fig$1]$.

2. Femur head diameter (FHD): the circumference of femoral head in craniocaudal axis [Fig-2].

3. Femur neck length (FNL): the distance between the base of femoral head and inter-trochanteric line [Fig-3].

4. Femur neck breadth (FNB): breadth of neck of femur in vertical axis.

5. Femur neck thickness (FNT): thickness of neck of femur in antero-posterior axis.

6. Femur neck shaft angle (FNSA): the angle between the long axis of head and neck (line joining the center of head of femur and the midpoint of inter-trochantric line) and long axis of shaft (vertical line from the tip of greater trochanter to the shaft of femur) [Fig-4].

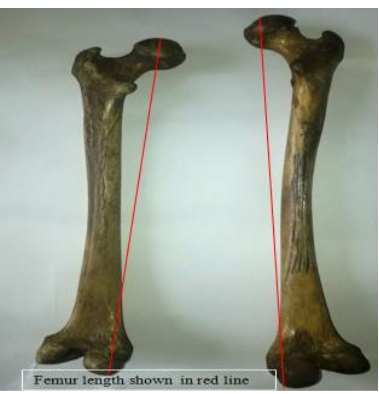

Figure 1: Measuring femur length

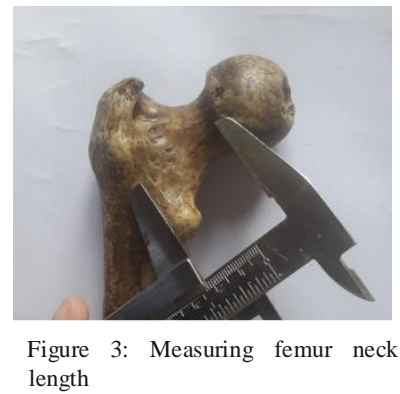

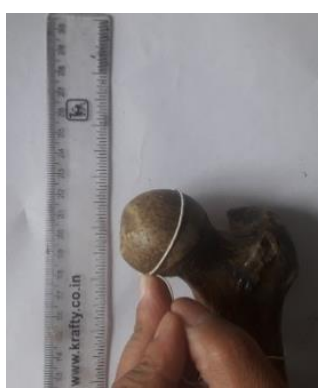

Figure 2: Measuring femur head diameter

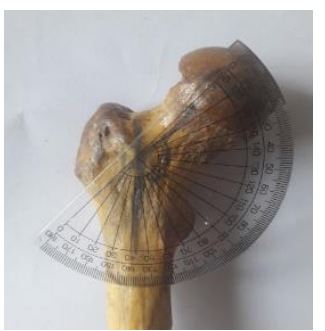

Figure 4: Measuring femur neck shaft angle 
All the measurements were recorded separately for right and left femur. The measurements were measured manually with the help of measuring scale, thread, osteometric board, protractor and vernier calliper. The collected data were represented as mean \pm SD then analyzed with MS Excel 2007 software and represented graphically. Independent t-test was used to calculated the differences in the parameters of right and left femur. P-value $<0.05$ was considered statistically significant.

\section{RESULTS}

The average femoral length for entire femur was $42 \pm 2.81 \mathrm{~cm}$, femoral head diameter was $13.05 \pm 0.9 \mathrm{~cm}$, femoral neck length was $4.12 \pm 0.32 \mathrm{~cm}$, femoral neck breadth was $2.94 \pm 0.30 \mathrm{~cm}$, and femoral neck thickness was $2.36 \pm 0.42 \mathrm{~cm}$. The femur neck shaft angle of left femur was significantly higher than that of right femur. (P-value 0.03) The mean results and standard deviation (SD) of different parameters of both right and left femur is summarized in Table 1.

Table 1. Different parameters of both femurs.

\begin{tabular}{|c|c|c|c|c|c|}
\hline S.N & Parameters & $\begin{array}{c}\text { Right femur } \\
\text { (35) }\end{array}$ & $\begin{array}{l}\text { Left femur } \\
\text { (40) }\end{array}$ & P-value & $\begin{array}{c}\text { Bilateral } \\
\text { femur } \\
(75)\end{array}$ \\
\hline 1 & Femur length & $42.70 \pm 3.09$ & $41.30 \pm 2.54$ & 0.31 & $42 \pm 2.81$ \\
\hline 2 & Femur head diameter & $13.10 \pm 0.88$ & $13.00 \pm 0.92$ & 0.17 & $13.05 \pm 0.9$ \\
\hline 3 & Femur neck length & $4.10 \pm 0.35$ & $4.14 \pm 0.30$ & 0.26 & $4.12 \pm 0.32$ \\
\hline 4 & Femur neck breadth & $2.95 \pm 0.28$ & $2.94 \pm 0.33$ & 0.17 & $2.94 \pm 0.30$ \\
\hline 5 & Femur neck thickness & $2.19 \pm 0.46$ & $2.53 \pm 0.38$ & 0.68 & $2.36 \pm 0.42$ \\
\hline 6 & $\begin{array}{l}\text { Femur neck shaft angle } \\
\text { (in degree) }\end{array}$ & $122.90 \pm 7.71$ & $131.30 \pm 5.17$ & 0.03 & $127.1 \pm 6.44$ \\
\hline
\end{tabular}




\section{DISCUSSION}

Manyprevious studies on adult femur have been carried out in different countries and many authors have studied the various parameters of femur using different materials and techniques such as cadaveric specimens, dry bones, Computed Tomography(CT) scans, Magnetic Resonance Imaging(MRI) scans and plain radiographs. The morphometric studies of proximal end of femur were conducted in Indian population, Pakistani population, Malayan population and in Chinese population. [8-11] These studies also favour the fact of regional difference in the parameters of proximal end of femur but the data obtained from these populations coincided more or less with the parameters obtained from the present study which was conducted in Nepalese population. Some frequently described measurements that are associated with an increased risk of fracture include a longer hip axis, length of femur, a larger neck shaft angle and a larger femoral neck width. [12] The femur neck length in present study was slightly more than by Branco et al. and Ravichandran et al. studies where as less than the Osorio et al. studies. [13-15] However, the results of the Gujar et al. studies were comparable with the present study. [16] The mean of femur neck length was more than that of Ravichandran et al. studies. [14] He found that the femur neck length to be between $2-4.8 \mathrm{~cm}$ as compared to $4.12 \mathrm{~cm}$ in the present study. The mean value of femur neck breadth and thickness in present study corroborate with the studies of Baharuddin et al.[17]

The study conducted by El-Kaissai et al., suggested that postmenopausal women with hip fracture have a longer femoral neck length as compared to women without hip fractures. [18] Calis et al. obtained a similar result in women, where the width and angle of femoral neck were significantly greater in patients with hip fractures. [19] In the present study mean neck length was $4.12 \pm 0.32 \mathrm{~cm}$, neck breadth was $2.94 \pm 0.30 \mathrm{~cm}$ and neck thickness was $2.36 \pm 0.42 \mathrm{~cm}$. In males with increase in age, neck thickness is also increased, which contribute to the development of osteoarthritis by increasing impingement. [20] According to the studies of Dolhain et al. The Synergy hip with a $131^{\circ}$ neck-shaft angle and a dual offset replaced hip more reliably than does the Mallory Head component with a valgus $135^{\circ}$ neck shaft angle. [21] In the present study femur neck shaft angle was found to be $127^{\circ}$. Ismail BM observed that femur head diameter in south Indian population was $4.19 \pm 0.19 \mathrm{~cm}$ was less comparable to present study. [22]

\section{CONCLUSION}

The dimensions of proximal end of femur in Nepalese population are different as compared to other countries. The knowledge of different dimensions of proximal end of femur will be important in anthropological and medico-legal practice as well as to orthopaedic surgeons for diagnosis, planning and treatment of disease related to hip and femur.

\section{CONFLICT OF INTEREST}

None

\section{SOURCES OF FUNDING}

None

\section{REFERENCES}

1. Moore KL, Dalley AF. Clinically Oriented Anatomy: 6th ed. Philadelphia / Elsevier; 2010. P. 517-20.

2. Dutta AK. Essentials of Human Anatomy-Superior and Inferior Extremities. 4th ed. Current Books International; 2010. P. 138-45.

3. Standring S, Borley NR, Gray H. Gray's anatomy: the anatomical basis of 
clinical practice. 41st ed. Edinburgh: Churchill Livingstone/Elsevier; 2016. P. 1379-42.

4. Gilligan I, Chandraphak S, Mahakkanukrauh P. Femoral neck-shaft angle in humans: variation relating to climate, clothing, lifestyle, sex, age and side. J Anat. 2013; 223:133-51. https://doi.org/10.1111/joa.12073

5. Birkenmaier C, Jorysz $\mathrm{G}$, Jansson $\mathrm{V}$, Heimkes B. Normal development of the hip: a geometrical analysis based on planimetric radiography. J Pediatr Orthop B. 2010; 19:1-8 https://doi.org/10.1097/BPB.0b013e3283 $2 \mathrm{f} 5 \mathrm{aeb}$

6. Eckhoff DG, Kramer RC, Watkins JJ, CA Alongi, DP Van Gerven. Variation in femoral anteversion. Clin Anat. 1994; 7:72-5.

https://doi.org/10.1002/ca.980070203

7. Jiang LS, Shen L, Dai LY. Intramedullary fixation of subtrochanteric fractures with long proximal femoral nail or long gamma nail: technical notes and preliminary results. Ann Acad Med Singapore. 2007;36(10):821-6.

https://www.ncbi.nlm.nih.gov/pubmed/17 987233

8. MinakshiVerma, Sheetal Joshi, Anita Tuli, Shashi Raheja, Priyanka Jain, Priyanka Srivastava. Morphometry of Proximal Femur in Indian Population. J Clin Diagn Res. 2017; 11(2): 1-4 https://dx.doi.org/10.7860\%2FJCDR\%2F 2017\%2F23955.9210

9. Umer M, Sepah YJ, Khan A, Wazir A, Ahmed M, Jawad MU. Morphology of the proximal femur in the Pakistan population. J Orthop Surg. 2010;18:27981.

https://doi.org/10.1177/23094990100180 0304
10. Baharuddin MY, Zulkifly AH, His M, Aziz AA. Three dimensional morphometry of the femur to design the total hip Arthroplasty for Malay Population. Advanced Science Letters. 2013;19(10):2982-87.

11. Lin KJ, Wei HW, Lin KP, Tsai CL, Lee PY. Proximal femoral morphology and the relevance to design of Anatomically precontoured plates: A study of the Chinese population. The Scientific World Journal.2014;106941:6 http://dx.doi.org/10.1155/2014/106941

12. Bhattacharya S, Chakraborty $P$, Mukherjee A. Correlation between neck shaft angle of femur with age and anthropometry: A Radiographic study. Indian Journal of basic and applied Medical Research. 2014;3(3):100-07.

13. De Sousa E, Fernandes R, Mathias $\mathrm{MB}$, Rodrigues MR, Ambram AJ, Babinski MA. Morphometric study of the proximal femur extremity in Brazilians. Int J Morphol. 2010;28(3):835-840.

14. D. Ravichandran, N Muthukumaravel, R. Jaikumar, Das H, Rajendran M. Pxoximal femoral geometry in Indians and its clinical applications. J Anat Soc India. 2011;60(1):6-12

15. Osorio H; Schorwer K.; Coronado C; Delgado J, Aravena P. Proximal femoral epiphysis anatomy in Chilean population. Orthopedic and forensic aspects. Int $\mathbf{J}$ Morphol. 2012;30(1):258-262. http://dx.doi.org/10.4067/S071795022012000100046

16. Gujar S, Vikani S, Parmar J, Bondre $\mathrm{KV}$. A correlation between femoral neck shaft angle to femoral neck length. IJBAR;2013:04(05):295-98. https://doi.org/10.7439/ijbar.v4i5.354

17. Baharuddin A MY, Kadir RA, Zulkifly AH, Saat A, Aziz AA, Lee M et 
al. Morphology study of the proximal femur in Malay population. Int $J$ Morphol., 2011;29(4):1321-25.

18. http://dx.doi.org/10.3923/jms.2011.21 3.219

19. El Kaissai S, Pasco JA, Henry MJ, Panahi S, Nicholson JG, Nicholson GC, et al. Femoral neck geometry and hip fracture risk: the Geelong osteoporosis study. Osteoporosis Int. 2005;16:1299303. https://doi.org/10.1007/s00198-0051988-z

20. Calis HT, Eryavuz M, Calis M. Comparison of femoral geometry among cases with and without hip fractures. Yonsei Med J. 2004;45:901-07. https://doi.org/10.3349/ymj.2004.45.5.90 1

21. Johnson JK, Renner JB, Dahners LE. Anteroposterior thickening of the femoral neck with aging decreases the offset in men. Am J Sports Med. 2012;40(10):2213- 17.

22. https://doi.org/10.1177/03635465124 57158

23. Dolhain P, Tsigaras H, Bourne RB, Rorabach CH, Donald SM, Mc Calden R. The effectiveness of dual offset stems in restoring offset during total hip replacement. Acta Orthop Belg. 2002;68(5):490-99.

24. Prasath RA, Ismail BM. A correlative study of morphometric analysis of acetabulum and femoral head in male and female south Indian human cadavers. Journal of Science. 2014;4(1):4-8. 